\title{
The Evolving Role of Brentuximab Vedotin in Classical Hodgkin Lymphoma
}

This article was published in the following Dove Press journal:

Blood and Lymphatic Cancer: Targets and Therapy

\section{Catherine Lai $\mathbb{D}^{\prime}$ \\ Adrese Michael Kandahari (D) Chaitra Ujjani ${ }^{2}$ \\ 'Lombardi Comprehensive Cancer Center, Medstar Georgetown University Hospital, Washington, DC, USA; ${ }^{2}$ Seattle Cancer Care Alliance, Fred Hutchinson CRC, University of Washington, Seattle, WA, USA}

\begin{abstract}
The arrival of the CD30 directed antibody-drug conjugate, brentuximab vedotin (BV), has altered the approach to patients with classical Hodgkin lymphoma. Since initial approval in 2011, BV has been extensively studied in previously untreated and relapsed/ refractory patients. Treatment indications for the antibody-drug conjugate have been expanded from the previously treated population to include maintenance therapy after autologous stem cell transplantation and recently, combination with chemotherapy in newly diagnosed advanced stage patients. This article will review the evolution of BV in classical Hodgkin lymphoma, detailing the studies that led to the approved indications and discussion of recent trials in combination with chemotherapy and immunotherapy.
\end{abstract}

Keywords: antibody-drug conjugate, brentuximab vedotin, CD30, immunotherapy, classical Hodgkin lymphoma, novel therapies

\section{Introduction}

Standard front-line regimens for classical Hodgkin lymphoma (cHL) have enabled durable remissions in $90 \%$ of early stage $^{1}$ and $75 \%$ of advanced stage patients. ${ }^{2}$ Unfortunately, 10-30\% will experience refractory or relapsed disease and only half of these patients are expected to achieve a long-term cure with high-dose chemotherapy followed by autologous stem cell transplantation (ASCT). ${ }^{3}$ As over 8000 new patients are diagnosed with cHL each year in the United States alone, ${ }^{4}$ there is a substantial need for more effective, novel therapies, particularly in the advanced stage and previously treated population.

The hallmark feature of cHL is the Reed-Sternberg (RS) cell, originated from B-cell lineage and characterized by high levels of CD30 expression. CD30 is a transmembrane glycoprotein of the TNF receptor superfamily that affects cell survival, proliferation, and apoptosis, and therefore is an ideal target for therapy in cHL. ${ }^{5}$ The antibody-drug conjugate brentuximab vedotin is comprised of a chimeric anti-CD30 IgG1 antibody linked to monomethyl auristatin E (MMAE), a microtubule-disrupting agent. Once bound to CD30, this complex is internalized, and lysosomal enzymes cleave the linker, releasing MMAE within the target cell and resulting in mitotic arrest and induction of apoptosis. ${ }^{6}$

\section{Brentuximab Vedotin Monotherapy}

Initial efforts with CD30 directed monoclonal antibodies (mAb) were clinically unsuccessful. One early preclinical study indicated robust in vivo binding of CD30 expressing RS cells with the murine Ber-H2 mAb in 6 patients, but unfortunately
Correspondence: Catherine Lai Lombardi Comprehensive Cancer Center, Medstar Georgetown University Hospital Washington, DC, USA

Tel + I-202-444-3735

Fax + I-202-444-0939

Email Catherine.lai@gunet.georgetown.edu 
there was no antitumor activity seen. ${ }^{7}$ Phase I and II studies of the chimeric anti-CD30 mAb, SGN-30, demonstrated tolerability, but lacked clinical activity. ${ }^{8,9}$ The human anti-CD30 mAb, MDX-060, performed slightly better and was able to produce two complete responses (CR) and two partial responses (PR) amongst 63 relapsed/ refractory patients, however, the median duration of response was only 2-5 months. ${ }^{10}$ From these studies, it was hypothesized that heavily pre-treated patients were unable to mount a sufficient antibody-dependent, cellmediated immune response. Consequently, antibody-drug conjugation was considered as a mechanism to circumvent a dependence of drug efficacy on host immune reactivity. Ber-H2-saporin, an anti-CD30 mAb conjugated to a potent ribosome inhibitor (saporin), produced PRs in 4 of $4 \mathrm{cHL}$ patients, but were of short duration (6-10 weeks). ${ }^{11}$ Francisco et al had previously reported the feasibility of conjugating SGN-30 mAb to MMAE in a murine model. By demonstrating conjugate stability with both potent and selective cellular apoptosis, ${ }^{6}$ this ultimately led to the development of SGN-35 (Adcetris; Seattle Genetics Inc), more recently known as brentuximab vedotin (BV).

Initial phase I trials investigating BV in relapsed/ refractory $\mathrm{cHL}$ demonstrated overall response rates (ORR) of $36-54 \%$ with CR of $21-29 \%$ in heavily pretreated patients. ${ }^{12,13}$ The relative durability of response allowed for bridging to more definitive therapies including stem cell transplantation. These data led to the hallmark phase II trial evaluating the clinical efficacy of BV in 102 cHL patients with relapsed/refractory disease after autologous stem cell transplantation (ASCT). ${ }^{14}$ Patients were administered $1.8 \mathrm{mg} / \mathrm{kg}$ of BV every three weeks for up to 16 doses. Patients received a median of nine doses, achieving an overall response rate (ORR) of $75 \%$ and $\mathrm{CR}$ of $34 \%$. The median time to objective response and CR was 5.7 weeks and 12 weeks, respectively. The median progression-free survival (PFS) was 9.3 months, and patients who achieved CR experienced a median duration of remission (DOR) of 20.5 months. With longer follow-up, the estimated 5-year PFS and overall survival (OS) was 22\% and $41 \%$, respectively, with 13 patients remaining in $\mathrm{CR}$ at five years. ${ }^{15}$ Peripheral neuropathy (PN) was the most common adverse event (55\%), which improved or resolved in $80 \%$ of those affected after dose modification or discontinuation. Given these remarkable data, BV was approved by the FDA for patients with $\mathrm{cHL}$ who had progressive disease after ASCT or who had received at least two prior lines of therapy and were deemed inappropriate for ASCT (Table 1).

Subsequent studies have been conducted evaluating BV monotherapy in the post-transplant setting. The AETHERA trial compared BV to placebo for high-risk patients after ASCT. ${ }^{16}$ In this phase III study, patients were considered at an increased risk for relapse if any of the following were present: primary refractory disease, relapse within 12 months of treatment, or extranodal involvement. Patients were randomized to receive BV $(1.8 \mathrm{mg} /$ $\mathrm{kg}$ ) or placebo within 30-45 days of ASCT every three weeks for up to 16 cycles $(n=329)$, although only half of the cohort was able to receive the full course of therapy. The BV arm was associated with a clinically significant improvement in PFS vs placebo (median PFS 42.9 months vs 24.1 months, $\mathrm{p}=0.0013)$. These data led to the approval of $\mathrm{BV}$ as a maintenance regimen for high-risk patients in the post-transplant setting (Table 1). Long-term follow-up data indicated that BV provided a five-year PFS of $59 \%$ compared to $41 \%$ with placebo (HR $0.52 ; 95 \% \mathrm{CI}$, $0.379-0.717){ }^{17}$

\section{Brentuximab in Combination with Chemotherapy}

In hopes of recreating the success of rituximab in B-cell malignancies expressing CD20, BV has been extensively studied in combination with chemotherapy. The first explorations were in the relapsed setting. The current approach for patients in first relapse is a platinum-based salvage regimen, such as ICE (ifosfamide, carboplatin, etoposide), in preparation for ASCT. BV in combination with standard cytotoxic salvage regimens, including ICE ${ }^{18,19}$ ESHAP (etoposide, methylprednisolone, highdose cytarabine, cisplatin), ${ }^{20}$ and DHAP (dexamethasone, high-dose cytarabine, cisplatin) ${ }^{21}$ have been evaluated in small early phase studies. BV with concurrent ICE produced a $\mathrm{CR}$ of $70 \%$ amongst 24 patients, with $86 \%$ proceeding to ASCT. ${ }^{19}$ The CR rates were modestly higher than previous reports with ICE alone $(\sim 60 \%))^{22,23}$ Likewise, BV in combination with ESHAP and DHAP produced CR rates of $75 \%$ and $80 \%$ respectively. ${ }^{20,21}$ These are promising interim analyses and longer follow data after final accrual are pending.

Bendamustine, a hybrid alkylating agent currently approved in NHL and CLL, has demonstrated activity in relapsed/refractory cHL patients (ORR 53\%, CR 33\%). ${ }^{24}$ As this drug has been administered successfully and safely 
Table I Studies That Led to FDA Approval of Brentuximab Vedotin

\begin{tabular}{|c|c|c|c|c|c|c|c|}
\hline Study & Regimen & Patient Type (N) & $\mathbf{F} / \mathbf{U}$ & ORR & CR & PFS & OS \\
\hline $\begin{array}{l}\text { Younes, }{ }^{14} \text { Chen }^{15} \\
\text { (5 year update) }\end{array}$ & BV & $\begin{array}{l}\text { Relapsed/Refractory } \\
\text { after ASCT (I02) }\end{array}$ & $\begin{array}{l}5 \\
\text { years }\end{array}$ & $75 \%$ & $\begin{array}{l}\mathrm{CR}=34 \% \\
\text { OS* }=64 \% \\
\text { PFS }=52 \%, \text { medians not } \\
\text { reached }\end{array}$ & $\begin{array}{l}22 \%, * \text { median } \\
9.3 \text { months }\end{array}$ & $\begin{array}{l}41 \% * \\
\text { median } 40.5 \\
\text { months }\end{array}$ \\
\hline \multirow{2}{*}{$\begin{array}{l}\text { Moskowitz }{ }^{16} \text { (AETHERA), } \\
\text { Moskowitz }{ }^{17} \text { (5 year } \\
\text { update) }\end{array}$} & BV & \multirow{2}{*}{$\begin{array}{l}\text { Consolidation } s / p \\
\text { ASCT in high risk pts } \\
(329)\end{array}$} & \multirow{2}{*}{$\begin{array}{l}5 \\
\text { years }\end{array}$} & \multirow[t]{2}{*}{-} & - & $59 \%$ & \multirow[t]{2}{*}{-} \\
\hline & Placebo & & & & & $41 \%$ & \\
\hline \multirow[t]{2}{*}{ Connors $^{32}$ (ECHELON-I) } & $\begin{array}{l}\mathrm{BV}+ \\
\mathrm{AVD} \\
\text { (AAVD) }\end{array}$ & \multirow[t]{2}{*}{$\begin{array}{l}\text { Treatment naïve Stage } \\
\text { III-IV disease (I334) }\end{array}$} & \multirow[t]{2}{*}{$\begin{array}{l}2 \\
\text { years }\end{array}$} & $86 \%$ & $73 \%$ & $\begin{array}{l}82.1 \% \\
\text { (Median) }\end{array}$ & $96.6 \%$ \\
\hline & $A B V D$ & & & $83 \%$ & $70 \%$ & $\begin{array}{l}77.2 \% \\
\text { (Median) }\end{array}$ & $94.2 \%$ \\
\hline
\end{tabular}

Notes: *estimated, ${ }^{+}$modified.

Abbreviations: $\mathrm{N}$, number of $\mathrm{cHL}$ patients on agent of interest; F/u, follow-up time; ORR, overall response rate; OS, overall survival; PFS, progression-free survival; CR, complete response rate; BV, brentuximab vedotin; AVD, doxorubicin+vinblastine+dacarbazine; AAVD, BV+doxorubicin+vincristine+dacarbazine; $A S C T$ autologous stem cell transplant, pts patients.

with monoclonal antibodies and immunotherapy in NHL, ${ }^{25-27}$ combination with BV was felt to be a reasonable consideration in cHL. LaCasce and colleagues first studied the combination of bendamustine $(90 \mathrm{mg} / \mathrm{kg})$ and BV $(1.8 \mathrm{mg} / \mathrm{kg})$ in a phase I/II study of 53 patients with previously treated disease. ${ }^{28}$ Patients achieved an ORR of 93\% after a median of two cycles with 74\% achieving a CR. Forty patients were able to proceed ASCT, 30 patients after just two cycles. Four of six patients who underwent ASCT in partial remission attained a CR. Estimated twoyear PFS and Kaplan-Meier estimated OS were 63\% and $95 \%$, respectively; the PFS for those who underwent ASCT was $70 \%$. Notably, there was no significant difference in OS between the group that underwent ASCT and the group that did not. A comparable response rate of $78 \%$ was reported amongst 37 patients in the phase II portion of a similar study. ${ }^{29}$ The combination of BV and bendamustine has become a popular outpatient option, providing a bridge to ASCT as well as a durable option for those not thought to be a candidate for ASCT.

Given the notable improvements in response in the relapsed setting, BV has also been investigated with front-line regimens. The addition of BV to the well-established standard ABVD (doxorubicin, bleomycin, vinblastine, dacarbazine) regimen was explored in a front-line phase I study of 25 patients with advanced stage cHL, producing a CR rate of $95 \% .{ }^{30}$ Due to considerable grade $3+$ pulmonary toxicity, however, the protocol was amended to omit bleomycin (AAVD). The utility of bleomycin has been questioned in previously untreated patients, and it was felt that BV potentiated its pulmonary effects. In 26 patients, the AAVD regimen was well-tolerated and induced CR of $96 \%$ with a 5 -year PFS of $92 \%{ }^{31}$

The phase III ECHELON-1 trial enrolled 1334 advanced stage patients to receive AAVD vs ABVD. ${ }^{32}$ The primary endpoint was two-year modified PFS, which used the standard criteria of disease progression and death, but also included patients who achieved a Deauville score of 3-5 after cycle 6 and received subsequent anticancer therapy. The 2-year modified PFS favored AAVD at $82.1 \%$ vs $77.2 \%(p=0.04)$, with a risk reduction of $23 \%$. With a statistically significant, albeit small clinical benefit of approximately 5\%, BV gained FDA approval in combination with AVD for previously untreated advanced stage cHL. Of note, increased adverse events occurred in the AAVD arm with two-thirds of patients developing grade 3-4 peripheral neuropathy. In addition, granulocyte colony-stimulating factor (G-CSF) prophylaxis was mandated due to unacceptable complications from neutropenia. With further analysis, it appears that this regimen would most benefit patients with stage IV disease, IPS of 4-7, young age, or more than one extra-nodal site.

Other studies have evaluated different schedules of BV when administered with chemotherapy (Table 2). Kumar et al reported a CR rate of $93 \%$ amongst 30 patients with unfavorable early stage disease who received four cycles of AAVD. ${ }^{33}$ Of note, 23 patients had bulky disease, including 14 with masses greater than $10 \mathrm{~cm}$. Twenty-five 
Table 2 Recent Clinical Trials with Brentuximab Vedotin Therapy

\begin{tabular}{|c|c|c|c|c|c|c|c|}
\hline Study & Regimen & Disease Setting (N) & $\mathbf{F} / \mathbf{U}$ & CR & ORR & PFS & OS \\
\hline Kumar $^{33}$ & $B V+A V D \pm R T$ & $\begin{array}{l}\text { High risk stage II } \\
\text { disease (30) }\end{array}$ & $\begin{array}{l}\text { Median } \\
\text { I8.8 } \\
\text { months }\end{array}$ & $\begin{array}{l}90 \% \text { after } 2 \text { cycles, } \\
93 \% \text { after } 4 \text { cycles, } \\
100 \% \text { of those } \\
\text { who received RT }\end{array}$ & - & $93.3 \%$ at I year & - \\
\hline \multirow[t]{2}{*}{ Eichenauer $^{36}$} & BrECADD & \multirow{2}{*}{$\begin{array}{l}\text { Advanced stage, } \\
\text { treatment naïve (104) }\end{array}$} & \multirow[t]{2}{*}{17 mos. } & $88 \%$ & \multirow{2}{*}{-} & $89 \%$ & \multirow[t]{2}{*}{-} \\
\hline & BrECAPP & & & $94 \%$ & & $95 \%$ & \\
\hline Evens $^{34}$ & $B V+A V D$ & $\begin{array}{l}\text { Treatment naïve (>60 } \\
\text { years) ( } 48)\end{array}$ & 2 years & $\begin{array}{l}36 \% \text { after BV only, } \\
90 \% \text { after AVD }\end{array}$ & $\begin{array}{l}82 \% \text { after BV } \\
\text { only, } 95 \% \\
\text { after AVD }\end{array}$ & $84 \%$ & $93 \%$ \\
\hline Herrera $^{48}$ & BV + nivolumab (BN) & $\begin{array}{l}\text { Relapsed/Refractory } \\
(61)\end{array}$ & $\begin{array}{l}\text { Median } \\
7.8 \\
\text { mos. }\end{array}$ & $61 \%$ & $82 \%$ & $\begin{array}{l}89 \%^{*}, \text { median } \\
\text { not reached at } \\
6 \text { months }\end{array}$ & - \\
\hline $\begin{array}{l}\text { Harker- } \\
\text { Murray }\end{array}$ & $\begin{array}{l}\text { BN, } \\
\text { BV + bendaumustine } \\
\text { intensification if } \\
\text { suboptimal response }\end{array}$ & $\begin{array}{l}\text { Relapsed/Refractory } \\
(<30 \text { years) prior to } \\
\text { ASCT (32) }\end{array}$ & _ & $\begin{array}{l}64 \% \text { after } \mathrm{BN} \text {, } \\
100 \% \text { after } \\
\text { intensification }\end{array}$ & $80 \%$ after $\mathrm{BN}$ & - & $100 \%$ \\
\hline \multirow[t]{2}{*}{ Diefenbach $^{49}$} & $\mathrm{BN}$ & \multirow[t]{2}{*}{$\begin{array}{l}\text { Relapsed/Refractory } \\
\text { (30) }\end{array}$} & \multirow[t]{2}{*}{2 years } & $61 \%$ & $88 \%$ & $\begin{array}{l}68 \%(\mathrm{I}-\mathrm{yr}) \\
\text { median not } \\
\text { reached }\end{array}$ & $\begin{array}{l}\text { median } \\
\text { not } \\
\text { reached }\end{array}$ \\
\hline & $\begin{array}{l}\text { BV + nivolumab + } \\
\text { ipilimumab }(\mathrm{BNI})\end{array}$ & & & $73 \%$ & $82 \%$ & $\begin{array}{l}72 \%(I-y r) \\
\text { median not } \\
\text { reached }\end{array}$ & $\begin{array}{l}\text { median } \\
\text { not } \\
\text { reached }\end{array}$ \\
\hline
\end{tabular}

Note: *estimated.

Abbreviations: $\mathrm{N}$, number of $\mathrm{cHL}$ patients on agent of interest; $\mathrm{F} / \mathrm{u}$, follow-up; ORR, overall response rate; OS, overall survival; PFS, progression free survival; CR, complete response; SSE, significant side effects; m, modified; BV, brentuximab vedotin; AVD, doxorubicin+vinblastine+dacarbazine; BN, BV+nivolumab; BrECADD, BV +etoposide+cyclophosphamide+doxorubicin+dacarbazine+dexamethasone; BrECAPP, BV+etoposide+cyclophosphamide+doxorubicin+procarbazine+prednisone; RT, radiation therapy; pts, patients.

patients in the study subsequently received consolidative involved site radiation therapy (ISRT), all of whom had a CR. At a median follow up of 18 months, the 1-year PFS was $93 \%$.

Evens et al explored a sequential approach to an elderly population with primary advanced stage disease, in which 48 patients received 2 doses of BV followed by 6 cycles of AVD followed by another 4 doses of BV. ${ }^{34}$ The response rates after the two lead-in doses of $\mathrm{BV}$ were comparable to the relapsed setting (ORR 82\%, CR 36\%), and improved considerably after patients completed the AVD portion (ORR 95\%, CR 90\%). The 2-year PFS was $84 \%$ but favored patients with a lower cumulative index score. This sequential approach allowed for a more tolerable degree of peripheral neuropathy: $4 \%$ grade 3 events and $33 \%$ grade 2 events. These adverse events were mostly reversible, preserving efficacy. Abramson and colleagues explored the concept of two lead-in doses of BV monotherapy followed by BV with AVD (AAVD) in nonbulky limited stage patients. ${ }^{35}$ Patients received 4-6 cycles of AAVD based on their interim PET scan results. All 34 patients achieved a CR and the 3-year PFS was $94 \%$. Despite the impressive activity, $62 \%$ of patients developed severe neutropenia, including an elderly patient who died of complications of sepsis during the first cycle of AAVD. Like ECHELON-1, the protocol was amended to include G-CSF prophylaxis. This group of investigators is also exploring the omission of vinblastine to minimize toxicity [NCT02505269].

Although ABVD is generally accepted as the front-line standard in cHL, the German Hodgkin Study Group HD21 trial evaluated $\mathrm{BV}$ with modified versions of the more intensive eBEACOPP (escalated bleomycin, etoposide, doxorubicin, cyclophosphamide, vincristine, procarbazine, prednisone) regimen in a randomized phase II study in advanced stage patients. ${ }^{36}$ By omitting the vincristine, 
the investigators were able to maintain efficacy (CR 88\%) without significant peripheral neuropathy. The current BRAPP2 trial is investigating the role for BV consolidation after two cycles of eBEACOPP and ISRT in patients with interim PET-2 positivity after two lead-in cycles of ABVD in early stage disease [NCT02298283] (Table 3). Additionally, studies are underway evaluating efficacy of combination $\mathrm{BV}$ in pediatric populations, including $\mathrm{BV}+$ AVD [NCT02979522] and BV + AV (adriamycin, vinblastine) [NCT02398240].

It is important to recognize that elderly patients may be unable to tolerate standard front-line regimens due to underlying comorbidities such as cardiomyopathy. Based on the encouraging relapsed/refractory data, the bendamustine-BV regimen was evaluated as a front-line regimen in a 20-patient study for those over the age of 60 years and considered ineligible for anthracycline-based chemotherapy. ${ }^{37}$ This doublet combination yielded a remarkable ORR of $100 \%$ with $88 \% \mathrm{CR}$; however, $65 \%$ of patients experienced serious side effects, including two deaths within the first 30 days of treatment, leading to discontinuation of bendamustine and study closure. The HALO trial evaluated the same combination in 22 advanced stage patients aged $60-80$ at a lower dose (BV $1.2 \mathrm{mg} / \mathrm{kg}$ every three weeks for six cycles). ${ }^{38}$ A lower CR rate of 59\% was seen; however, 13 of these 15 patients completed the full 6 cycles of therapy and 10 maintained a $\mathrm{CR}$ at 9 month follow-up. The attenuated dose of BV appears to be more manageable for older patients when combined with bendamustine, but more long-term data are necessary to understand whether this is a feasible front-line regimen.

\section{Brentuximab and Checkpoint Inhibition}

Unique to cHL, malignant RS cells make up only a small fraction of tumor bulk $(\sim 1 \%)$, and are surrounded by a

Table 3 Current Clinical Trials with Brentuximab Vedotin Therapy

\begin{tabular}{|c|c|c|c|c|c|}
\hline NCT \# & Regimen & Phase & Disease Setting & $\begin{array}{l}\text { Estimated } \\
\text { Enrollment }\end{array}$ & $\begin{array}{l}\text { Primary } \\
\text { Endpoint }\end{array}$ \\
\hline $\begin{array}{l}\text { NCT02298283 } \\
\text { (BRAPP2) }\end{array}$ & $\begin{array}{l}\text { BV consolidation after eBEACOPP } \\
\text { and ISRT escalation }\end{array}$ & II & $\begin{array}{l}\text { - supradiaphragmatic stage I-II with Deauville } \\
\text { score }>3 \text { after } 2 \text { cycles of ABVD }\end{array}$ & 40 (actual) & Two-year PFS \\
\hline $\begin{array}{l}\text { NCT03I38499 } \\
\text { (CheckMate 8I2) }\end{array}$ & $\mathrm{BV}$ vs $\mathrm{BN}$ & III & - R/R patients after ASCT or ineligible for ASCT & 340 & $\begin{array}{l}\text { PFS up to four } \\
\text { years }\end{array}$ \\
\hline NCT03057795 & BN consolidation post-ASCT & II & $\begin{array}{l}\text { - high risk relapsed or refractory patients } \\
\text { - BV naive or no progression with prior BV } \\
\text { therapy }\end{array}$ & 65 & I8-month PFS \\
\hline NCT027587I7 & $\begin{array}{l}\text { BN in those unsuitable for } \\
\text { standard therapy }\end{array}$ & II & $\begin{array}{l}\text { - treatment naive } \\
\text { - age } \geq 60 \text { or } \mathrm{EF}<50 \% \text { or DLCO }<80 \% \text {, or } \\
\mathrm{CrCl} 30-60 \mathrm{~mL} / \mathrm{min}\end{array}$ & 75 & ORR \\
\hline NCT0I7I6806 & $\begin{array}{l}\text { BV monotherapy vs BV + } \\
\text { dacarbazine vs BV + bendamustine } \\
\text { vs BV + nivolumab }\end{array}$ & II & $\begin{array}{l}\text { - treatment naive } \\
\text { - > } 75 \mathrm{YO} \text { or }>60 \mathrm{YO} \text { with reduced } \mathrm{EF} \text { or } \mathrm{CrCl}\end{array}$ & 160 & $\begin{array}{l}\text { ORR up to } 16 \\
\text { months }\end{array}$ \\
\hline NCT037I 2202 & $\begin{array}{l}\text { PET/CT-2 negative: BN vs ABVD } \\
\text { +nivolumab } \mathrm{PET} / \mathrm{CT}-2 \text { positive: } \\
\text { AAVD } \pm \text { nivolumab }\end{array}$ & II & $\begin{array}{l}\text { - Treatment naïve early stage patients having } \\
\text { received } 2 \text { lead-in cycles of ABVD followed by } \\
\text { interval PET/CT-2 }\end{array}$ & 264 & I8-month PFS \\
\hline NCT03233347 & $\begin{array}{l}\text { AAVD } \times 3 \text { cycles } \rightarrow \\
\text { Interim PET }+\rightarrow \text { BN } \\
\text { Interim PET }-\rightarrow \text { nivolumab only }\end{array}$ & II & - treatment naive non-bulky early stage patients & 82 & 3-year PFS \\
\hline NCT0I703949 & $\mathrm{BV}$ vs $\mathrm{BN}$ & II & - R/R patients after at least 2 cycles of $B V$ & 40 & ORR \\
\hline NCT030I3933 & BV, cyclosporine, and verapamil & I & - R/R after at least one line of therapy & 39 & MTD \\
\hline
\end{tabular}

Abbreviations: PFS, progression free survival; MTD, max tolerated dose; AE, adverse event; ORR, objective response rate; CR, complete response rate; pts, patients; r/r, relapsed/refractory; ASCT, autologous stem cell transplant; BV, brentuximab vedotin; eBEACOPP, escalated bleomycin+etoposide+ doxorubicin+cyclophosphamide +vincristine+procarbazine+prednisone; ISRT, involved site radiation therapy; ABVD, doxorubicin+bleomycin+ vincristine+dacarbazine; AAVD, BV+doxorubicin+vincristine +dacarbazine; AAV, BV+doxorubicin+vincristine; BN, brentuximab+nivolumab; PML, progressive multifocal leukoencephalopathy; PD-(L)I, programmed cell death protein I or programmed death-ligand I; EF, ejection fraction; DLCO, diffusing capacity of the lung for carbon monoxide; $\mathrm{CrCl}$, creatinine clearance. 
dense inflammatory infiltrate of T- and B- lymphocytes, histiocytes, neutrophils, eosinophils, and stromal cells. ${ }^{39,40}$ Domination of the tumor microenvironment by suppressive CD4+ T-lymphocytes ${ }^{41}$ secondary to RS cell chemokine and cytokine secretion ${ }^{42,43}$ as well as T-lymphocyte exhaustion by programmed cell death protein 1 (PD-1) activation creates a unique opportunity for intervention with immune checkpoint inhibitors (CPI). CPI, namely PD-1 inhibitors, have demonstrated impressive ORRs of $66-69 \%{ }^{44,45}$ in relapsed/refractory cHL, leading to accelerated FDA approval of anti-PD-1 IgG4 mAbs, nivolumab and pembrolizumab, in relapsed/refractory cHL (after failed ASCT in the case of nivolumab). PD-1 inhibition is effective due to the significant overexpression of programmed death-ligand 1 (PD-L1) by RS cells in cHL, which is secondary to chromosome 9p24.1 amplification. ${ }^{46}$ PD-1 activation on T-lymphocytes leads to decreased antigen recognition and effector function, thereby promoting cancer cell survival. ${ }^{47}$ Inhibiting this signal by binding either PD-1 or PD-L1 allows the immune system to execute previously blocked immune surveillance and allow for cancer cell death.

Despite their impressive ORRs, the CR rates with CPI are lower, ${ }^{44,45}$ thus leaving room for their investigation in combination with other therapies. CPIs are capable of achieving more robust responses when administered with novel agents, even in the post-ASCT salvage setting. The combination of BV $1.8 \mathrm{mg} / \mathrm{kg}$ and nivolumab $3 \mathrm{mg} / \mathrm{kg}$ for four cycles in $61 \mathrm{cHL}$ patients at first relapse produced an ORR of $82 \%$ and CR of $61 \%,{ }^{48}$ with 54 patients successfully proceeding to ASCT. Of note, immune-related reactions (IRR) occurred in $44 \%$ of patients, though most were mild, necessitating only $8 \%$ of patients to undergo systemic corticosteroid therapy. There was no significant correlation between IRR and ASCT outcomes noted in the study, although follow-up was relatively short.

BV has been studied with dual immunotherapy agents in a multi-arm phase I study with nivolumab and ipilimumab, an anti-CTLA-4 (cytotoxic T-lymphocyte-associated protein 4) inhibitor. ${ }^{49}$ As part of this study, 18 patients (7 s/p ASCT) received $\mathrm{BV}+$ nivolumab and attained an ORR of $88 \%$ and CR of $61 \%$, comparable to prior reports with this doublet. The 1-year PFS was $68 \%$ and median OS was not reached after a median follow-up of two years. Twenty-one patients (9 s/p ASCT) were treated with BV + ipilimumab and achieved ORR of $76 \%$ and CR of $57 \%$; 1-year PFS was $60 \%$ and median OS not reached after a median follow-up of three years. In the triplet arm of BV with nivolumab and ipilimumab, the ORR was $82 \%$ among 22 patients $(9 \mathrm{~s} / \mathrm{p}$ ASCT). The CR rate and 1-year PFS was modestly higher at $73 \%$ and $72 \%$. Toxicities were mostly of grades I-II severity, although there were two deaths related to pneumonitis in the cohorts treated with nivolumab. This study has been expanded and is currently enrolling patients randomized to $\mathrm{BV}+$ nivolumab vs $\mathrm{BV}+$ nivolumab + ipilimumab in relapsed and refractory patients [NCT01896999]. While the initial responses have been encouraging, longer follow up is necessary to understand the durability of this approach. Additionally, a randomized design is necessary to better understand the benefit of dual immunotherapy over a single immunotherapeutic when administered with BV.

\section{Retreatment with Brentuximab Vedotin}

As indications for BV expand, an area of clinical concern is efficacy with retreatment and the development of resistance. In vitro and in vivo cHL models demonstrate that $\mathrm{BV}$ resistance may be linked to intrinsic MMAE resistance as well as MMAE transport (namely by MDR1) to the extracellular space. ${ }^{50}$ Retreatment with BV has been explored in a small study of 21 patients who developed progressive disease after previously achieving a response with a brentuximab containing regimen. Retreatment with BV produced an ORR of up to $60 \%$ and CR of $30 \%{ }^{51}$ The estimated median duration of response was 9.2 months, ranging from 0-19.5+ months. As expected, there was an increased incidence of peripheral motor neuropathy that was primarily low grade. Based on preclinical data indicating that $\mathrm{BV}$ can initiate a localized antitumor response and the hypothesis that BV may have synergy with nivolumab, the addition of nivolumab to BV is being explored in patients who have had an initial inadequate response to BV [NCT01703949].

\section{Toxicities with Brentuximab Vedotin}

Toxicities from BV differ from other antibody therapy given the drug conjugation with a cytotoxic agent MMAE. Some of the more common toxicities include neuropathy and neutropenia. Over $50 \%$ of patients experience peripheral neuropathy when given as monotherapy and $25 \%$ with combination treatment, with most cases being grade one and two. ${ }^{14,52}$ Most commonly, the median time to onset is around 12 weeks or after four cycles of treatment. The majority of patients improve after dose 
holding or dose reduction with resolution typically occurring within 12 weeks. Neutropenia occurs in approximately $20 \%$ of patients, typically at grade 3 or higher but is often transient. ${ }^{14,52}$ Dose delays occurred in $15 \%$ of patients but no increase in febrile neutropenia was seen. IRRs are seen within the first 1-2 cycles and typically occur in over $50 \%$ of patients but are only considered serious in $15 \%$ of patients. Rash can be seen in about $10-30 \%$ of patients and more serious events such as Stevens-Johnson syndrome (SJS) and toxic epidermal necrolysis (TEN) are very rare occurring at a rate less than $0.1 \%{ }^{53}$ Besides SJS and TEN, other rare but serious adverse events include: progressive multifocal leukoencephalopathy, pancreatitis, pulmonary toxicity, and hepatoxicity. The pulmonary toxicity is significantly more common when used in combination with ABVD and for this reason the use of $\mathrm{BV}$ with bleomycin is contraindicated. ${ }^{53}$

\section{Conclusion}

A greater understanding of the pathophysiology of classical Hodgkin lymphoma has enabled researchers to identify and develop effective targeted therapies that have improved outcomes for patients. These novel agents have addressed an unmet need, particularly in the relapsed setting after ASCT. The CD30-directed antibody-drug conjugate, BV, was the first to be approved for these patients with an otherwise dismal prognosis. The addition of BV to established chemotherapy regimens for cHL has shown great promise as a bridge to ASCT and eventually led to its current front-line approval with AVD. Unfortunately, the clinical benefit of AAVD is relatively modest over ABVD, restricted to a select sub-population, and associated with significantly increased toxicity. BV may benefit a broader population by allowing for reduced cycles or even omission of other cytotoxic chemotherapeutics, however, longer follow up of the previously mentioned and ongoing studies is necessary to answer these questions. Additionally, the incorporation of immune checkpoint inhibition provides an opportunity to offer a more targeted approach and potentially eliminate conventional chemotherapy. Next steps in clinical investigation need to more clearly define where BV belongs within the treatment algorithm, recognizing this ought to be tailored to patient-specific features such as age, stage, and prognostic features. Although $\mathrm{cHL}$ has traditionally been considered a favorable malignancy, it is imperative to continue research efforts into unique trial designs and strategies to further the field and benefit future patients.

\section{Disclosure}

The authors report no conflicts of interest in this work.

\section{References}

1. Engert A, Plutschow A, Eich HT, et al. Reduced treatment intensity in patients with early-stage Hodgkin's lymphoma. $N$ Engl $J$ Med. 2010;363(7):640-652. doi:10.1056/NEJMoa1000067

2. Merli F, Luminari S, Gobbi PG, et al. Long-term results of the HD2000 trial comparing ABVD versus BEACOPP versus COPPEBV-CAD in untreated patients with advanced Hodgkin lymphoma: a study by Fondazione Italiana Linfomi. J Clin Oncol. 2016;34 (11):1175-1181. doi:10.1200/JCO.2015.62.4817

3. Nieto Y, Popat U, Anderlini P, et al. Autologous stem cell transplantation for refractory or poor-risk relapsed Hodgkin's lymphoma: effect of the specific high-dose chemotherapy regimen on outcome. Biol Blood Marrow Transplant. 2013;19(3):410-417. doi:10.1016/j. bbmt.2012.10.029

4. American Cancer Society Facts and Figures. 2019. Available from: https://www.cancer.org/research/cancer-facts-statistics/all-cancerfacts-figures/cancer-facts-figures-2019.html. Accessed November 25, 2019.

5. Younes A, Kadlin ME. Emerging applications of the tumor necrosis factor family of ligands and receptors in cancer therapy. J Clin Oncol. 2003;21(18):3526-3534. doi:10.1200/JCO.2003.09.037

6. Francisco JA, Cerveny CG, Meyer DL, et al. cAC10-vcMMAE, an anti-CD30-monomethyl auristatin E conjugate with potent and selective antitumor activity. Blood. 2003;102(4):1458-1465. doi:10.1182/ blood-2003-01-0039

7. Falini B, Flenghi L, Fedeli L, et al. In vivo targeting of Hodgkin and Reed-Sternberg cells of Hodgkin's disease with monoclonal antibody Ber-H2 (CD30): immunohistological evidence. $\mathrm{Br} J$ Haematol. 1992;82(1):38-45. doi:10.1111/j.1365-2141.1992.tb04591.x

8. Bartlett NL, Younes A, Carabasi MH, et al. A phase 1 multidose study of SGN-30 immunotherapy in patients with refractory or recurrent CD30+ hematologic malignancies. Blood. 2008;111(4):18481854. doi:10.1182/blood-2007-07-099317

9. Forero-Torres A, Leonard JP, Younes A, et al. A phase II study of SGN-30 (anti-CD30 mAb) in Hodgkin lymphoma or systemic anaplastic large cell lymphoma. Br J Haematol. 2009;146(2):171-179. doi:10.1111/bjh.2009.146.issue-2

10. Ansell SM, Horwitz SM, Engert A, et al. Phase I/II study of an antiCD30 monoclonal antibody (MDX-060) in Hodgkin's lymphoma and anaplastic large-cell lymphoma. J Clin Oncol. 2007;25(19):27642769. doi:10.1200/JCO.2006.07.8972

11. Falini B, Bolognesi A, Flenghi L, et al. Response of refractory Hodgkin's disease to monoclonal anti-CD30 immunotoxin. Lancet. 1992;339(8803):1195-1196. doi:10.1016/0140-6736(92) 91135-U

12. Younes A, Bartlett NL, Leonard JP, et al. Brentuximab vedotin (SGN-35) for relapsed CD30-positive lymphomas. $N$ Engl J Med. 2010;363(19):1812-1821. doi:10.1056/NEJMoa1002965

13. Fanale MA, Forero-Torres A, Rosenblatt JD, et al. A phase I weekly dosing study of brentuximab vedotin in patients with relapsed/refractory CD30-positive hematologic malignancies. Clin Cancer Res. 2012;18(1):248-255. doi:10.1158/1078-0432.CCR-11-1425

14. Younes A, Gopal AK, Smith SE, et al. Results of a pivotal phase II study of brentuximab vedotin for patients with relapsed or refractory Hodgkin's lymphoma. J Clin Oncol. 2012;30(18):2183-2189. doi:10.1200/JCO.2011.38.0410

15. Chen R, Gopal AK, Smith SE, et al. Five-year survival and durability results of brentuximab vedotin in patients with relapsed or refractory Hodgkin lymphoma. Blood. 2016;128(12):1562-1566. doi:10.1182/ blood-2016-02-699850 
16. Moskowitz CH, Nademanee A, Masszi T, et al. Brentuximab vedotin as consolidation therapy after autologous stem-cell transplantation in patients with Hodgkin's lymphoma at risk of relapse or progression (AETHERA): a randomized, double-blind, placebo-controlled, phase 3 trial. Lancet. 2015;385(9980):1853-1862. doi:10.1016/S0140-6736 (15)60165-9

17. Moskowitz CH, Walewski J, Nademanee A, et al. Five-year PFS from the AETHERA trial of brentuximab vedotin for Hodgkin lymphoma at high risk of progression or relapse. Blood. 2018;132 (25):2639-2642. doi:10.1182/blood-2018-07-861641

18. Moskowitz AJ, Schoder H, Yahalom J, et al. PET-adapted sequential salvage therapy with brentuximab vedotin followed by augmented ifosfamide, carboplatin, and etoposide for patients with relapsed and refractory Hodgkin's lymphoma: a non-randomised, open-label, single-centre, phase 2 study. Lancet Oncol. 2015;16(3):284-292. doi:10.1016/S1470-2045(15)70013-6

19. Cassaday RD, Fromm JR, Cowan AJ, et al. Radiographic and highthroughput sequencing (HTS)-based response assessment after brentuximab vedotin (BV) plus ifosfamide, carboplatin, and etoposide (ICE) for relapsed/refractory (rel/ref) classical Hodgkin lymphoma (cHL): updated results of a phase I/II trial. Blood. 2017;130(Suppl 1):2806.

20. Garcia-Sanz R, Sureda A, Gonzalez AP, et al. Brentuximab vedotin plus ESHAP (BRESHAP) is a highly effective combination for inducing remission in refractory and relapsed Hodgkin lymphoma patients prior to autologous stem cell transplant: a trial of the Spanish Group of Lymphoma and Bone Marrow Transplantation (GELTAMO). Blood. 2016;128(22):1109.

21. Hagenbeek A, Mooij H, Zijlstra J, et al. Phase I dose-escalation study of brentuximab-vedotin combined with dexamethasone, high-dose cytarabine and cisplatin, as salvage treatment in relapsed/refractory classical Hodgkin lymphoma: the HOVON/LLPC Transplant BRaVE study. Haematologica. 2019;104(4):e151-e153. doi:10.3324/ haematol.2018.196899

22. Moskowitz CH, Nimer SD, Zelenetz AD, et al. A 2-step comprehensive high-dose chemoradiotherapy second-line program for relapsed and refractory Hodgkin disease: analysis by intent to treat and development of a prognostic model. Blood. 2001;97(3):616-623. doi:10.1182/blood.V97.3.616

23. Moskowitz CH, Matasar MJ, Zelenetz AD, et al. Normalization of pre-ASCT, FDG-PET imaging with second-line, non-cross-resistant, chemotherapy programs improves event-free survival in patients with Hodgkin lymphoma. Blood. 2012;119(7):1665-1670. doi:10.1182/ blood-2011-10-388058

24. Moskowitz AJ, Hamlin PA Jr, Perales MA, et al. Phase II study of bendamustine in relapsed and refractory Hodgkin lymphoma. J Clin Oncol. 2013;31(4):456-460. doi:10.1200/JCO.2012.45.3308

25. Rummel MJ, Niederie N, Maschmeyer G, et al. Bendamustine plus rituximab versus CHOP plus rituximab as first-line treatment for patients with indolent and mantle-cell lymphomas: an open-label, multicetre, randomized, phase 3 non-inferiority trial. Lancet. 2013;381(9873):1203-1210. doi:10.1016/S0140-6736(12)61763-2

26. Flinn IW, van der Jagt R, Kahl BS, et al. Randomized tiral of bendamustine-rituximab or R-CHOP/R-CVP in first-line treatment of indolent NHL or MCL: the BRIGHT study. Blood. 2014;123 (19):2944-2952. doi:10.1182/blood-2013-11-531327

27. Sehn LH, Chua N, Mayer J, et al. Obinutuzumab plus bendamustine versus bendamustine monotherapy in patients with rituximab-refractory indolent non-Hodgkin lymphoma (GADOLIN): a randomized, controlled, open-label, multicenter, phase 3 trial. Lancet Oncol. 2016;17(8):1081-1093. doi:10.1016/S1470-2045(16)30097-3

28. LaCasce AS, Bociek RG, Sawas A, et al. Brentuximab vedotin plus bendamustine: a highly active first salvage regimen for relapsed or refractory Hodgkin lymphoma. Blood. 2018;132(1):40-48. doi:10.1182/blood-2017-11-815183
29. O'Connor OA, Lue JK, Sawas A, et al. Brentuximab vedotin plus bendamustine in relapsed or refractory Hodgkin's lymphoma: an international, multicentre, single-arm, phase 1-2 trial. Lancet Oncol. 2018;19(2):257-266. doi:10.1016/S1470-2045(17)30912-9

30. Younes A, Connors JM, Park SI, et al. Brentuximab vedotin combined with ABVD or AVD for patients with newly diagnosed Hodgkin's lymphoma: a phase 1, open-label, dose-escalation study. Lancet Oncol. 2013;14(13):1348-1356. doi:10.1016/S1470-2045(13)70501-1

31. Connors JM, Ansell SM, Fanale M, Park SI, Younes A. Five-year follow-up of brentuximab vedotin combined with ABVD or AVD for advanced-stage classical Hodgkin lymphoma. Blood. 2017;130 (11):1375-1377. doi:10.1182/blood-2017-05-784678

32. Connors JM, Jurczak W, Straus DJ, et al. Brentuximab vedotin with chemotherapy for stage III or IV Hodgkin's lymphoma. $N$ Engl J Med. 2018;378(4):331-344. doi:10.1056/NEJMoa1708984

33. Kumar A, Casulo C, Yahalom J, et al. Brentuximab vedotin and AVD followed by involved-site radiotherapy in early stage, unfavorable risk Hodgkin lymphoma. Blood. 2016;128(11):1458-1464. doi:10.1182/blood-2016-03-703470

34. Evens AM, Advani RH, Helenowski IB, et al. Multicenter phase II study of sequential brentuximab vedotin and doxorubicin, vinblastine, and dacarbazine chemotherapy for older patients with untreated classical Hodgkin lymphoma. J Clin Oncol. 2018;36(30):3015-3022. doi:10.1200/JCO.2018.79.0139

35. Abramson JS, Arnason JE, LaCasce AS, et al. Brentuximab vedotin, doxorubicin, vinblastine, and dacarbazine for non-bulky limited stage classical Hodgkin lymphoma. Blood. 2019;134(7):606-613. doi:10.1182/blood.2019001272

36. Eichenauer DA, Plutschow A, Kreissl S, et al. Incorporation of brentuximab vedotin into first-line treatment of advanced classical Hodgkin's lymphoma: final analysis of a phase 2 randomised trial by the German Hodgkin Study Group. Lancet Oncol. 2017;18(12):16801687. doi:10.1016/S1470-2045(17)30696-4

37. Friedberg JW, Forero-Torres A, Bordoni RE, et al. Frontline brentuximab vedotin in combination with dacarbazine or bendamustine in patients aged $\geq 60$ years with HL. Blood. 2017;130(26):2829-2837. doi:10.1182/blood-2017-06-787200

38. Gallamini A, Bijou F, Viotti J, et al. Brentuximab-vedotin and bendamustine is a feasible and effective drug combination as first-line treatment of Hodgkin lymphoma in the elderly (HALO TRIAL). Hematol Oncol. 2017;35(Suppl 2):170. doi:10.1002/hon.2438_28

39. Kuppers R, Rajewsky K, Zhao M, et al. Hodgkin disease: Hodgkin and Reed-Sternberg cells picked from histological sections show clonal immunoglobulin gene rearrangements and appear to be derived from B cells at various stages of development. Proc Natl Acad Sci USA. 1994;91(23):10962-10966. doi:10.1073/pnas.91.23.10962

40. Kanzler H, Kuppers R, Hansmann ML, Rajewsky K. Hodgkin and ReedSternberg cells in Hodgkin's disease represent the outgrowth of a dominant tumor clone derived from (crippled) germinal center B cells. $J$ Exp Med. 1996;184(4):1495-1505. doi:10.1084/jem.184.4.1495

41. Marshall NA, Christie LE, Munro LR, et al. Immunosuppressive regulatory $\mathrm{T}$ cells are abundant in the reactive lymphocytes of Hodgkin lymphoma. Blood. 2004;103(5):1755-1762. doi:10.1182/ blood-2003-07-2594

42. van den Berg A, Visser L, Poppema S. High expression of the CC chemokine TARC in Reed-Sternberg cells. A possible explanation for the characteristic T-cell infiltrate in Hodgkin's lymphoma. Am J Pathol. 1999;154(6):1685-1691. doi:10.1016/S0002-9440(10)65424-7

43. Vardhana S, Younes A. The immune microenvironment in Hodgkin lymphoma: T cells, B cells, and immune checkpoints. Haematologica. 2016;101(7):794-802. doi:10.3324/haematol.2015.132761

44. Younes A, Santoro A, Shipp M, et al. Nivolumab for classical Hodgkin's lymphoma after failure of both autologous stem-cell transplantation and brentuximab vedotin: a multicenter, multicohort, single-arm phase 2 trial. Lancet Oncol. 2016;17(9):1283-1294. doi:10.1016/S1470-2045(16)30167-X 
45. Chen R, Zinzani PL, Fanale MA, et al. Phase II study of the efficacy and safety of pembrolizumab for relapsed/refractory classic Hodgkin lymphoma. J Clin Oncol. 2017;35(19):2125-2132. doi:10.1200/ JCO.2016.72.1316

46. Green MR, Monti S, Rodig SJ, et al. Integrative analysis reveals selective 9p24.1 amplification, increased PD-1 ligand expression, and further induction via JAK2 in nodular sclerosing Hodgkin lymphoma and primary mediastinal large B-cell lymphoma. Blood. 2010;116 (17):3268-3277. doi:10.1182/blood-2010-05-282780

47. Yamamoto R, Nishikori M, Kitawaki T, et al. PD-1 PD-1 ligand interaction contributes to immunosuppressive microenvironment of Hodgkin lymphoma. Blood. 2008;111(6):3220-3224. doi:10.1182/ blood-2007-05-085159

48. Herrera AF, Moskowitz AJ, Bartlett NL, et al. Interim results of brentuximab vedotin in combination with nivolumab in patients with relapsed or refractory Hodgkin lymphoma. Blood. 2018;131 (11):1183-1194. doi:10.1182/blood-2017-10-811224

49. Diefenbach CS, Hong F, Ambinder R, et al. Extended follow-up of a phase I trial of ipilimumab, nivolumab, and brentuximab vedotin in relapased Hodgkin lymphoma: a trial of the ECOG-ACRIN Research Group (E4412). Hematol Oncol. 2019;37:(S2):123-4. doi:10.1002/ hon.83 2629
50. Bartlett NL, Chen R, Fanale MA, et al. Retreatment with brentuximab vedotin in patients with CD30-positive hematologic malignancies. J Hematol Oncol. 2014;7:24. doi:10.1186/1756-8722-7-24

51. Chen R, Hou J, Newman E, et al. CD30 downregulation, MMAE resistance, and MDR1 upregulation are all associated with resistance to brentuximab vedotin. Mol Cancer Ther. 2015;14(6):1376-1384. doi:10.1158/1535-7163.MCT-15-0036

52. Pro B, Advani R, Brice P, et al. Bretuximab vedotin (SGN-35) in patients with relapsed or refractory systemic anaplastic large-cell lymphoma: results of a phase II study. J Clin Oncol. 2012;30 (18):2190-2196. doi:10.1200/JCO.2011.38.0402

53. ADCETRIS [package insert]. Bothell, WA: Seattle Genetisc; 2015. Available from: http://www.adcetris.com/pdf/ADCETRIS-brentuxi mab-vedotin-Prescribing-Information.pdf. Accessed November 25, 2019.

54. Kelly KM, Daw S, Mauz-Korholz C, et al. Response-adapted treatment with nivolumab and brentuximab vedotin in young patients with relapsed/refractory classical Hodgkin lymphoma: checkmate 744 subgroup analyses. Hematol Oncol. 2019;37:56-57. doi:10.1002/ hon.26_2629

\section{Publish your work in this journal}

Blood and Lymphatic Cancer: Targets and Therapy is an international, peer-reviewed, open access journal focusing on blood and lymphatic cancer research, identification of therapeutic targets and the optimal use of preventative and integrated treatment interventions to achieve improved outcomes, enhanced survival and quality of life for the cancer patient. The manuscript management system is completely online and includes a very quick and fair peer-review system. Visit http://www.dovepress.com/testimonials.php to read real quotes from published authors. 